\title{
Analysis of solar lithium bromide-water absorption cooling system with heat pipe solar collector
}

\author{
Amir Falahatkar ${ }^{1, *}$, M. Khalaji Assadi ${ }^{1}$ \\ ${ }^{1}$ Department of Energy Engineering, Science \& Research Branch, Islamic Azad University, Tehran, Iran \\ *Corresponding Author. Tel: +98 912 2506923, Email: eng.falahatkar@srbiau.ac.ir
}

\begin{abstract}
Solar energy applications in Iran for supplying domestic hot water, space heating and cooling have been considered severely in last decade. The purpose of this research is to analysis of solar single effect lithium bromide-water absorption cooling system in a typical office building in Tehran. The solar energy is absorbed by heat pipes and stored in an insulated storage tank. This system has been designed to supply the cooling load of mentioned typical office building where the cooling load is $35.17 \mathrm{KW}$ ( 10 tons of refrigerant) which events in July. Results demonstrate that depending on the Tehran climate and the specification of the building by means of optimized design of solar heat pipe collectors, up to $2400 \mathrm{~m}^{3} /$ year Natural Gas energy saving can be reached by use of solar absorption cooling system. Achieving this purpose requires utilizing 16 collectors which everyone compromises 30 tubes with total absorber area of $45 \mathrm{~m}^{2}$ which is the optimum collector area for this plant in Tehran. According to this replacement the investment payback rate would be 13 years which would be much shorter than the payback time of a solar cooling system combined with conventional all air systems.
\end{abstract}

Keywords: Absorption cooling, Heat pipe collector, Solar energy

\section{Nomenclature}

\begin{tabular}{|c|}
\hline \\
\hline specific heat.......................j. $\mathrm{kg}^{-1} \cdot \mathrm{c}^{-1}$ \\
\hline 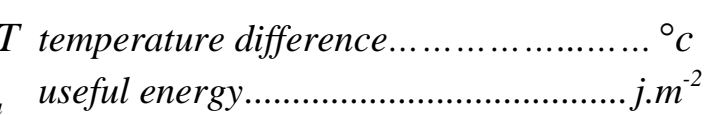 \\
\hline thermal efficiency .................................. \% \\
\hline $\begin{array}{l}\text { monthly average daily total solar radiation } \\
\text { on a horizontal surface...................j.m }\end{array}$ \\
\hline
\end{tabular}

$\beta$ slope ..................................................degree

$\rho_{g}$ diffuse reflectance of the ground.......degree

$\delta$ deviation angle ..................................degree

C capital cost .............................................\$

E energy saving................................. \$.year ${ }^{-1}$

PB payback time..........................year

$i$ energy inflation..............................\%

$\omega_{\text {s }}$ sunset hour angle.......................degree

\section{Introduction}

The energy demand for refrigeration and air-conditioning appliances has been increased continuously in last decades. World energy demand-and $\mathrm{CO}_{2}$ emissions- is expected to rise by some $60 \%$ by 2030 respect to the beginning of this century [1]. The cooling load in summer is associated with high solar energy, which offers a suitable opportunity to utilize solar energy for cooling. Conventional vapor compression chillers require high quality energy, electricity which is produced from initial energy resources. Furthermore, vapor compression cooling systems use chlorofluorocarbons (CFCs) and hydrochlorofluorocarbons (HCFCs) as working fluids. These materials will lead to global warming and ozone depletion. Thermal-driven air-conditioning systems are using heat as motive energy to provide cold energy. These systems can be categorized on absorption systems, adsorption systems, duplex rankine, desiccant cooling and ejector refrigeration systems. The heat could be obtained from waste heat sources, combined heat and power technologies (CHP), and solar energy. Lithium Bromide ( $\mathrm{LiBr}$ )-water absorption cooling systems are conventional in thermal-driven air-conditioning systems and have too many benefits in comparison with other cooling 
systems; because their performance is good and cost is low. The single effect LiBr-water absorption systems operate at a generator temperature range 70 to $95^{\circ} \mathrm{C}$ and the coefficient of performance (COP) of these systems are between 0.6 to 0.8 , which are higher than $\mathrm{NH} 3-\mathrm{H}_{2} \mathrm{O}$ absorption cooling systems [2].

Sparber et al [3] reported that till 2007 there were 81 installed large scale solar cooling systems, eventually including systems which are currently not in operation. 73 installations are located in Europe, 7 in Asia, China in particular, and 1 in America (Mexico). 60\% of these installations are dedicated to office buildings, $10 \%$ to factories, $15 \%$ to laboratories and education centers, $6 \%$ to hotels and the left percentage to buildings with different final use (hospitals, canteen, sport center, etc). They also cited that 56 installations are belong to absorption systems and the overall cooling capacity of the thermally driven chillers amounts to 9 MW 31\% of it is installed in Spain, 18\% in Germany and $12 \%$ in Greece.

Bong et al [4] designed and installed solar absorption chiller in Singapore. The system included 7KW absorption chiller, heat pipe collectors with a total area of $32 \mathrm{~m}^{2}$, a hot water storage tank, an auxiliary heater and a $17.5 \mathrm{KW}$ cooling tower. They cited that the overall average cooling capacity provided was $4 \mathrm{KW}$, solar fraction of $39 \%$ and COP of 0.58 .

Balghouthi et al [5] accomplished a simulation using TRNSYS program in order to select and size different components of solar absorption chiller. They reported that solar absorption cooling systems were suitable for Tunisian's condition.

Alizadeh et al [6] simulated and optimized a solar LiBr-water absorption cooling system that has been design for Malaysia using evacuated tube solar collectors. The modeling of the solar absorption chiller was accomplished with TRNSYS program.

Yeung et al [7] designed and installed a solar driven absorption chiller at the University of Hong Kong. This system included 4.7KW absorption chiller, flat plate collectors with a total area of $38.2 \mathrm{~m}^{2}$, a cooling tower, a $2.75 \mathrm{~m}^{3}$ hot water storage tank and the other equipments. They reported that the collector efficiency was estimated at $37.5 \%$, the annual system efficiency at $7.8 \%$ and an average solar fraction at 55\%, respectively.

The objective of this work is to evaluate and investigate the energy conservation capacity of a sample office building in Tehran, using solar LiBr-water absorption chiller and heat pipe solar collector. Furthermore, the payback time for initial investments of the system has been calculated.

\section{Methodology}

A cooling system possessing solar-operated absorption chiller provides the cooling demands for the typical office building in Tehran-Iran. Tehran is located at $35.68^{\circ} \mathrm{N}$ and $51.32^{\circ} \mathrm{E}$. Figure 1 demonstrates both the variability of ambient temperature and relative humidity and in figure 2 the monthly solar radiation on horizontal surface is demonstrated. The office has a single storey and its floor area is $280 \mathrm{~m}^{2}$. The daily occupancy schedule is from 8:00 to 17:00, totally 9hours and the daily cooling system schedule is considered during June 1 to September 22. The daily average of global solar radiation of Tehran is about $23 \mathrm{Mj} / \mathrm{m}^{2}$ for the summer months [8]. The major components of the plant are heat pipe solar collectors, a $35.17 \mathrm{KW}$ (10 RT) single effect LiBr-water absorption chiller, a hot water storage tank, a cooling tower, a control system and some other auxiliary equipments. 

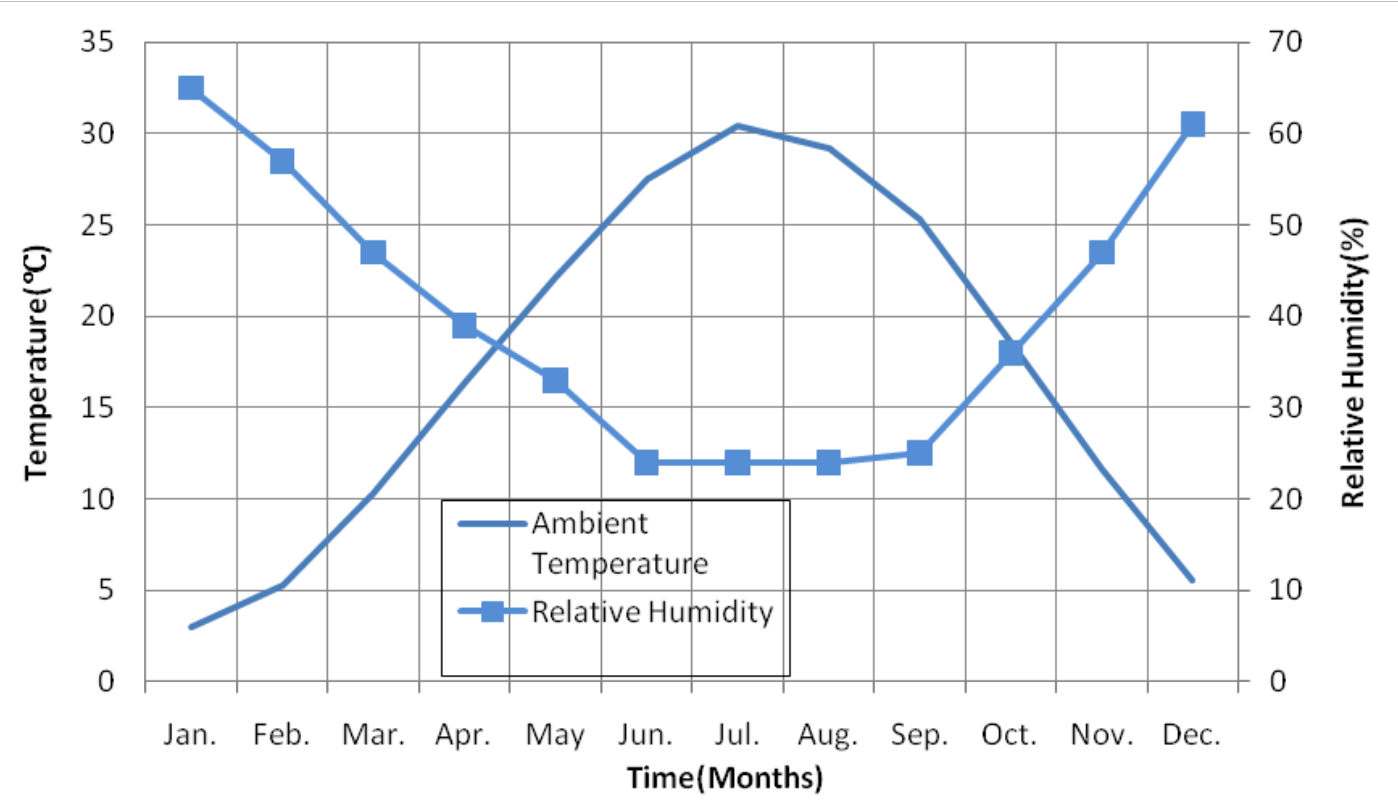

Fig. 1. Variability of ambient monthly temperature and monthly relative humidity for Tehran.

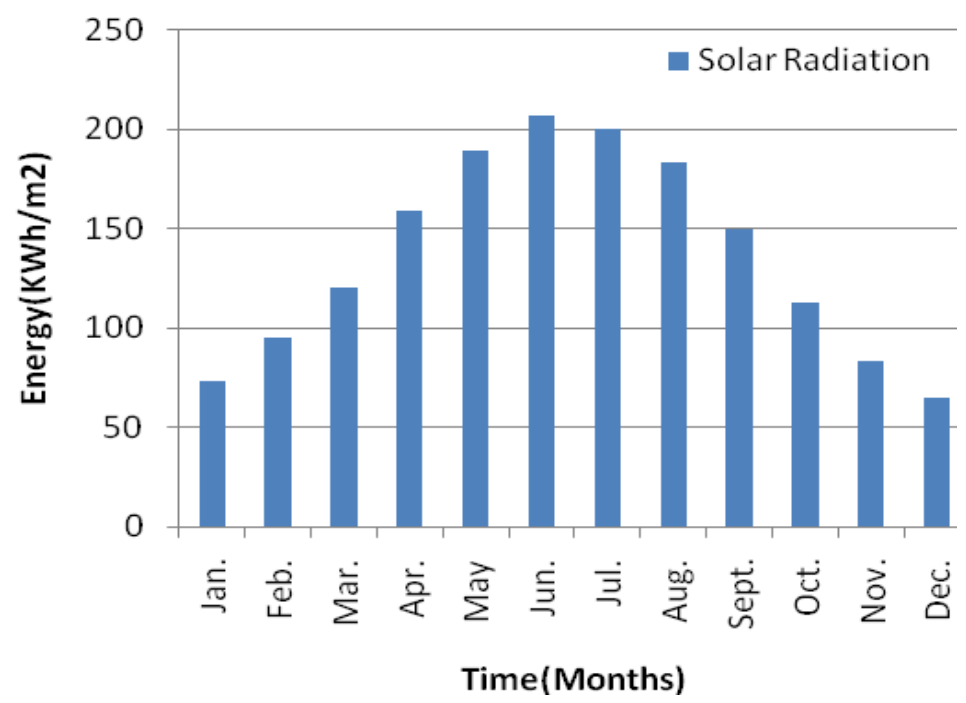

Fig. 2. Monthly solar radiation on horizontal surface in Tehran.

\subsection{Solar Energy}

The plant primary energy source is the solar energy, which is absorbed by heat pipe solar collector and stored in an insulated storage tank. Heat pipes are widely used for heat recovery and energy saving in various ranges of applications because of their simple structure, special flexibility, high efficiency, good compactness and excellent reversibility [9]. The heat pipe vacuum tube collects heat from the sun at high efficiency. It is important that heat pipe solar collectors must be installed with a tilt of at least $25^{\circ}$. They operate like a thermal diode where the flow of heat is in one direction only [10]. This type of collector commonly filled with alcohol or water in a vacuum and operates in two versions, one with a dry and one with a wet connection [11]. The most important difference between evacuated tube solar collectors and heat pipe solar collectors is that the heat carrier fluid inside of the copper heat pipe is not connected to the solar loop. The heat pipe collectors are mounted on a roof and tilted by $25^{\circ}$ with the roof to utilize more radiation in summer and it is produced by APRICUS. 


\subsection{Absorption chiller}

A water fired chiller (WFC) with a related capacity of 35.17KW cooling (10RT) produced by YAZAKI when it is operating at a hot water driving temperature of $88^{\circ} \mathrm{C}$, coolant water temperature of $31^{\circ} \mathrm{C}$ and output chilled water at $7^{\circ} \mathrm{C}$. The coefficient of performance (COP) of this chiller is 0.7 as reported by the manufacture.

\subsection{Presentation of parameters}

The thermal capacity of the equipments is determined by Eq. (1):

$$
Q=\stackrel{\circ}{m} \cdot c_{p} \cdot \Delta T,
$$

Where $\dot{m}$ is the mass flow rate, $c_{p}$ is the specific heat at constant pressure and $\Delta T$ is the temperature difference.

The energy during a fixed period is determined by Eq. (2):

$$
E=\int_{t i}^{t o} Q d t
$$

Where $t_{i}$ is initial time and $t_{o}$ is final time. Afterwards, the efficiency of solar collectors is obtained by Eq. (3) [2]:

$\eta=\frac{q_{u}}{\bar{R} \cdot \bar{H}}$

Where $q_{u}$ is the useful energy output of a collector per square meter, $\bar{H}$ is monthly average daily total solar radiation on a horizontal surface. It should be noted that the efficiency of solar heat pipe collector is about $63 \%$ as reported by the manufacture. $\bar{R}$ is the proportion of monthly average total radiation on tilted surface on the monthly average total radiation on horizontal surface which is determined by Eq. (4) [2]:

$$
\bar{R}=\left(1-\frac{\overline{H_{d}}}{\bar{H}}\right) \overline{R_{b}}+\frac{\overline{H_{d}}}{\bar{H}}\left(\frac{1+\cos \beta}{2}\right)+\rho_{g}\left(\frac{1-\cos \beta}{2}\right),
$$

Where $\overline{H_{b}}$ is monthly average daily beam solar radiation on a horizontal surface, $\overline{H_{d}}$ is monthly average daily diffuse solar radiation on a horizontal surface, $\rho_{g}$ is the diffuse reflectance of the ground and $\beta$ is the slope of the collector, $\overline{R_{b}}$ is the ratio of the average daily beam radiation on the tilted surface on that on a horizontal surface which is determined by Eq. (5) [2]: 


$$
\overline{R_{b}}=\frac{\cos (\phi-\beta) \cos \delta \sin \omega_{s}^{\prime}+\left(\frac{\pi}{180}\right) \omega_{s}^{\prime} \sin (\phi-\beta) \sin \delta}{\cos \phi \cos \delta \sin \omega_{s}+\left(\frac{\pi}{180}\right) \omega_{s} \sin \phi \sin \delta}
$$

Where $\omega_{s}^{\prime}$ is the sunset hour angle for the tilted surface for the mean day of the month and $\omega_{s}$ is the sunset hour angle, which are obtained by Eq. (6) and Eq. (7) [2]:

$$
\omega_{s}^{\prime}=\operatorname{Min}\left[\begin{array}{l}
\cos ^{-1}(-\tan \phi \tan \delta) \\
\cos ^{-1}(-\tan (\phi-\beta) \tan \delta)
\end{array}\right]
$$

Where $\varphi$ is the latitude and $\delta$ is the solar deviation angle.

$\omega_{s}=\cos ^{-1}(-\tan \varphi \tan \delta)$

\section{Results}

\subsection{Determining the optimum solar collector area}

With calculating $\bar{R}$ through equations 4 to 7 , the useful energy output of a collector is determined. Figure 4 demonstrates the monthly energy derived from one square meter of collector in Tehran. The surface area for the heat pipe collector is determined by the proportion of the required energy for cooling the environment on the useful energy output of the collector.

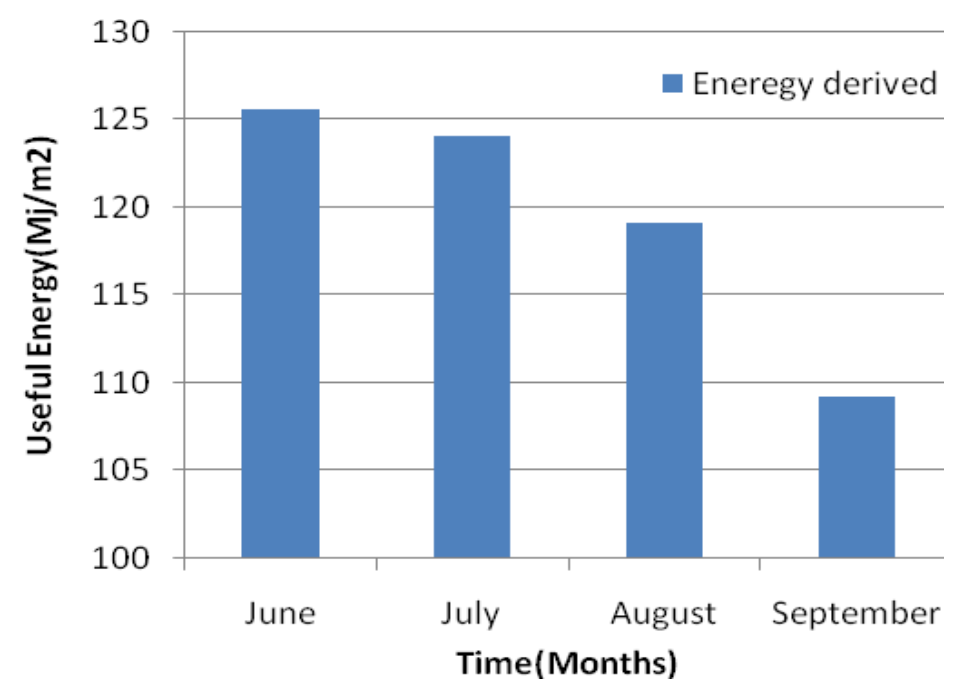

Fig. 3. Monthly energy derived from one square meter of collector in Tehran from June to September

Optimized solar collector area depends on some important factors such as: Solar radiation, intensity, cost increasing and amount of consumption [12]. To estimate the optimal surface of heat pipe solar collector, we should determine the solar cooling fraction (SCF). The solar cooling fraction is described as the ratio of solar heat yield to the total energy required to drive solar absorption chiller. 
Finally, the optimum surface of heat pipe collectors for typical office building in Tehran is determined in each situation as presented as figure. 4 .

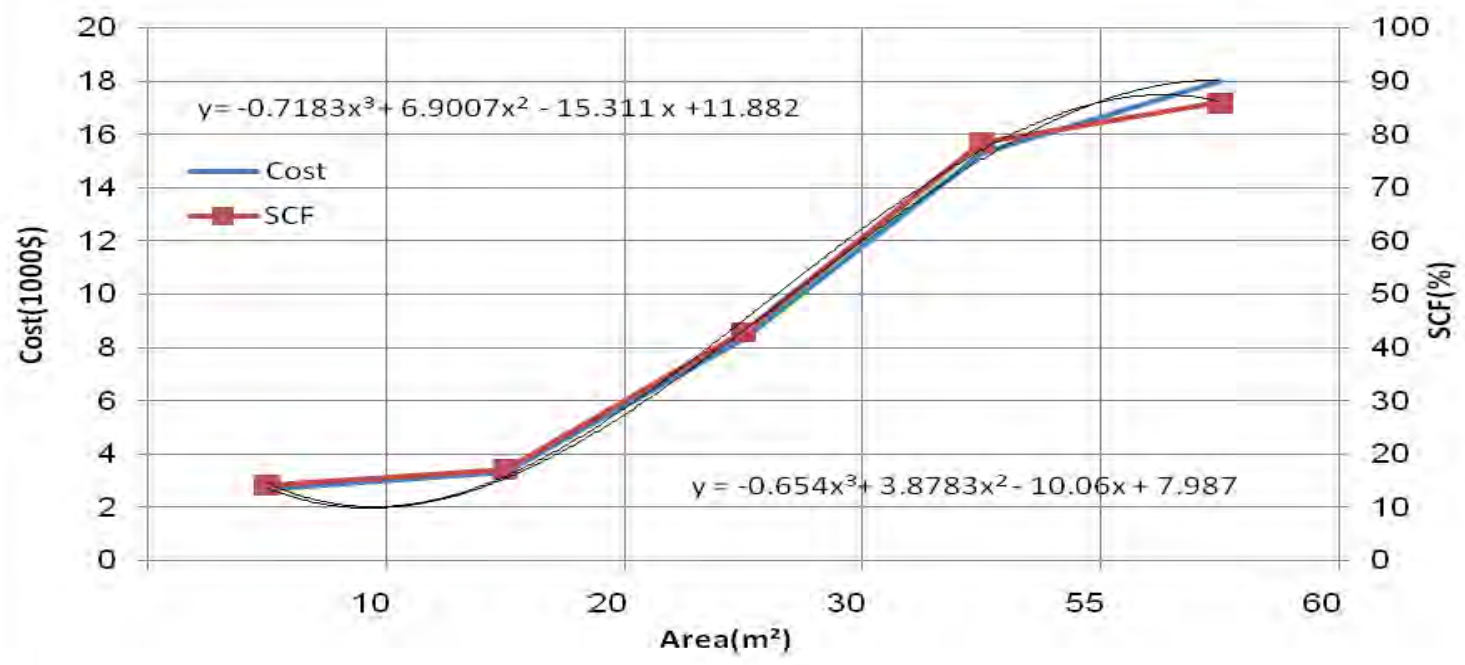

Fig. 4. Estimation of optimum solar heat pipe collectors for typical office building in Tehran

\subsection{Economic analysis}

Solar systems are commonly known by high investment and low operating cost. In order to estimate the payback time, total annual energy saving must be determined.

The payback time is determined by Eq. (8) [13]:

$$
P B=\frac{\log \left[\frac{C}{E} \cdot \frac{i}{100}+1\right]}{\log \left[1+\frac{i}{100}\right]}
$$

Where $C$ is the capital cost of installed solar cooling equipment, $E$ is the energy saving, $i$ is the energy inflation and $P B$ is the payback time.

The cost of equipments are summurized in table 1 and the cost of energy is shown in table 2 .

Table 1. Cost of equipments

\begin{tabular}{cc}
\hline Equipment & Cost \\
\hline LiBr-H2O Absorption chiller & $500 \$ / \mathrm{KW}$ \\
Heat pipe solar collector & $278 \$ / \mathrm{m}^{2}$ absorber area \\
Auxiliary heater & $50 \$ / \mathrm{KW}$ \\
Storage tank & $790 \$ / \mathrm{m}^{3}$ \\
Cooling tower & $65 \$ / \mathrm{KW}$ \\
\hline
\end{tabular}

Table 2. Cost of Energy

\begin{tabular}{cc}
\hline Energy & Cost \\
\hline Electricity & $0.330 \$ / \mathrm{KWh}$ \\
Oil & $1.580 \$ / \mathrm{t}$ \\
Natural Gas & $0.40 \$ / \mathrm{m}^{3}(2010)$ \\
\hline
\end{tabular}


Furthermore, during the economic analysis some basic assumptions are needed, such as maintenance costs, installation costs, the energy inflation and natural gas heating value. The maintenance costs are $1 \%$ of investments cost [13], installation costs are $12 \%$ of the equipment costs [14], the energy inflation is about 2\% [5] and natural gas heating value is about $38376 \mathrm{Kj} / \mathrm{m}^{3}$.

Consequently, the total energy and money saving are shown in table 3.

Table 3. total energy and money saving

\begin{tabular}{ccc}
\hline $\begin{array}{c}\text { Annual energy saving } \\
(\mathrm{MWh})\end{array}$ & $\begin{array}{c}\text { Annual money saving } \\
(\$)\end{array}$ & $\begin{array}{c}\text { Annual natural gas saving } \\
\left(\mathrm{m}^{3}\right)\end{array}$ \\
\hline 25.5 & 960 & 2400 \\
\hline
\end{tabular}

Thus, with calculating $P B$ through equation 8 , the payback time is estimated approximately 13 years which would be reasonable for solar cooling systems.

\section{Conclusions}

In this investigation the technical and economical analysis for single effect LiBr-water solar absorption system was done. The analysis was accomplished for a typical office building in Tehran. The plant provided air conditioning for a floor space of $280 \mathrm{~m}^{2}$. Furthermore, the plant included an auxiliary fossil system and its capacity was about 13KW. The most important advantage of this system is that it offers the highest environmental benefits. The other advantage is that we utilize the highest total energy saving.

It was shown that the solar cooling fraction for mentioned office building was $64.3 \%$ and the optimum solar heat pipe collector area was $45 \mathrm{~m}^{2}$. It means that this plant utilizes 16 collectors which everyone compromises 30 tubes. Finally, the payback time of this plant was estimated about 13 years.

\section{References}

[1] P. Bermejo, F. Javier Pino, F. Rosa, Solar absorption cooling plant in Seville, Solar Energy 84, 2010, pp. 1503-1512.

[2] JA. Duffie, WA. Beckman, Solar engineering of thermal processes, Wiley, Third edition, 2006, pp. 579-587

[3] W. Sparber, A. Napolitano, P. Melograno, Overview on worldwide installed solar cooling systems, Proceedings of 2nd international conference on Solar air conditioning, 2007, Spain

[4] T.Y. Bong, K.C. NG, A.O. Tay, Performance study of a solar powered air conditioning system, Solar Energy 39, 1987, pp. 173-182.

[5] M. Balghouthi, M. Hachemi Chahbani, A. Guizani, Solar powered air conditioning as a solution to reduce environmental pollution in Tunisia, Desalination 185, 2005, 105-10.

[6] F. Assilzadeh, SA. Kalogirou, Y. Ali, K. Sopian, Simulation and optimization of a Libr solar absorption cooling system with evacuated tube collectors, Renewable Energy 30, 2005, pp. 1143-1159. 
[7] M.R. Yeung, P.K. Yuen, A. Dunn, L.S. Cornish, Performance of a solar powered air conditioning system in Hong Kong, Solar Energy 48, 1992, pp. 309-319.

[8] B. Safaie, M. Khalaji Aassadi, H. Taghizadeh, A. Jilavi, G. Taleghani, M. Danesh, The evaluation of solar radiation potential in Iran, Proceeding of 19th international conference on Power System, 2004, Iran.

[9] R. Parand, B. Rashidian, A. Ataei, KH. Shakibi, Modeling the transient response of the thermosyphon heat pipes, Journal of Applied Sciences 9(8), 2009, pp. 1531-1537.

[10]J. Facao, A.C. Oliveira, Analysis of a plate heat pipe solar collector, International Journal of low carbon technologies.

[11]The German solar energy society, Planning and installing solar thermal systems, Earthscan, Second edition, 2010, pp. 30-33

[12]A. Ataei, M. Khalaji Assadi, R. Parand, N. Sharee, M. Raoufinia, A.H Kani, Solar combisystems a new solution for space heating in buildings, Journal of Applied Sciences 9(8), 2009, pp.1458-1465.

[13]G. Zidianakis, Th. Tsoutsos, N. Zografakis, Simulation of a solar absorption cooling system, proceeding of 28th conference on building low energy cooling and advanced ventilation technologies in the 21st century, 2007, 1187-1194

[14] M. Peters, K. Timmerhaus, R. West, Plant design and economic for chemical engineers, McGraw-Hill, Forth edition, 1991. 